\title{
SIMULTANEOUS MULTIPLE ROUND ASCENDING BID AUCTION AS AN EFFECTIVE METHOD OF SPECTRUM ALLOCATION
}

\author{
Agnieszka KUŚ \\ Pope John Paul II State School of Higher Education in Biała Podlaska, Faculty of Economic Sciences; \\ a.kus@dydaktyka.pswbp.pl, ORCID: 0000-0002-6258-6823
}

Purpose: The purpose of this paper is to characterize the rules of Simultaneous Multiple Round Ascending bid auction (SMRA) and to indicate factors confirming that it is an effective way of allocating radio frequencies.

Design/methodology/approach: The paper draws on the literature on the spectrum auction. Theoretical discussions are supported by the real-world examples of spectrum auction.

Findings: The paper presents the possibilities of modifying Simultaneous Multiple Round Ascending bid auction rules to adapt it to a specific market.

Originality/value: The analysis made in this paper could help policy makers in Poland and other countries in spectrum auction designing.

Keywords: spectrum auction, auction rules, SMRA.

Category of the paper: General review.

\section{Introduction}

Simultaneous multiple round ascending bid auction (SMRA) is an auction rule, which was designed and first used in 1994 in the United States for the sale of spectrum licenses. Before the auction, licenses in the US were granted to interested entities for free as a result of administrative decisions called "beauty contests" or lotteries. The total value of cellular licenses that the US government distributed in the 1980s at no charge was $\$ 46$ billion. An incentive to change the approach regarding the way the spectrum was allocated was the situation that took place in 1989, when one of the companies, after receiving a license for free, sold it for USD 41 million. Congress decided then that it could not ignore such large amounts and decided to replace this way of allocation with auctions, the use of which was proposed by the Nobel Prize winner in economics Ronald Harry Coase as early as in 1958 (McMillan, 1994). 
The Federal Communications Commission (FCC), which is the US regulatory authority, involved a large number of scientists to develop the rules of SMRA. They used the latest achievements in mathematical economics and game theory to develop an auction rule that would be appropriate for selling rights to use radio frequencies. During the public debate, which took place at that time, the regulator and the companies and experts in the field of auction designing were figuring out which of the available formats of auction will work better when selling a large number of licenses: the standard open auction format (called English auction) or the classic tender (called first price sealed bid auction). It was also discussed whether spectrum licenses should be sold one after the other, for example in consecutive single-object English auctions, or whether they should be sold simultaneously. As a result, an innovative option was chosen in the form of open bidding with the simultaneous sale of all items. It turned out to be a good choice, as the revenues from the series of SMRA auctions organized at that time turned out to be much higher than the organizers' expectations ${ }^{1}$. At the first SMRA in July 1994, 10 licenses were sold for a total of USD 617 million. A few months later another auction took place, the revenue of which turned out to be even higher: 99 licenses were sold at that time for a total amount of over USD 7 billion (Cramton, 1997; Milgrom, 1998).

The huge success of the first simultaneous multiple round ascending bid auction has become an inspiration for many other countries, making it one of the most widely used auction rule for selling radio frequencies worldwide. In Europe, SMRA was used for the first time in 2000-2001 during spectrum auctions for third-generation UMTS mobile telephony systems ${ }^{2}$. In Polish literature, there are only a few studies regarding the spectrum auctions and most of them contain only general information about this auction format (Kuśmierczyk, 2010; Lewczuk, 2006). A more exact analysis of SMRA in the context of the first spectrum auction in Poland should be found in the paper by Sobolewski and Formański (Sobolewski, Formański, 2014).

The purpose of this paper is to present the detailed rules of SMRA and to indicate its characteristics confirming that it is an effective spectrum allocation format. The paper also presents the possibilities of modifying this rule developed based on of many years of experience in other countries, allowing it to eliminate its few disadvantages.

\footnotetext{
${ }^{1}$ The US Office of Management and Budget estimated that the revenues from the series of SMRA organized at that time would amount to USD 10.6 billion, in fact, it turned out to be twice as high (McMillan, 1994; Cramton, 1998)

${ }^{2}$ Poland did not decide to use the auction to sell the spectrum licenses at that time. Instead, the government sold licenses to three incumbent operators for the same price for all entities, 650 million euros, which gave a fairly high result compared to other countries distributing spectrum at that time (Kuśmierczyk, 2010)
} 


\section{The specificity of spectrum auctions designing}

The process of spectrum auction designing is quite specific. This is because that spectrum is a scarce recourse and is characterized by strong complementarity. The marginal value of the second block for the bidder is higher than the first one. In addition, the value of the block is much higher if the block is adjacent to the band which the buyer already held ${ }^{3}$. Spectrum licenses sold at auction may also be substitutes (Cramton and Ockenfels, 2017). Substitutability can be created by the regulator artificially by not specifying the exact frequency ranges for the blocks sold, and sometimes there may be a natural way: for example, when the regional licenses are sold and some of them cover the same area. Due to the mentioned above properties, the participants of spectrum auctions are exposed to the so-called fragmentation risk (aggregation risk). After the auction, it may turn out that the buyers have failed to bid the amount of spectrum that allows them to implement the development plan they adopted, or the frequency blocks they bid are not adjacent, which reduces the possibility of their effective use. In both these cases, the actual value of the awarded spectrum is less than the amount you have to pay for it (Cramton, 2013).

Another type of risk faced by spectrum auction participants is the so-called exposure risk. The actual value of the frequency block purchased depends not only on the amount of spectrum that the buyer managed to acquire but also on the amount of spectrum auctioned by its competitors. If one entity obtains a decidedly larger frequency package than other auction participants, they gain an advantage on the market, because the larger amount of spectrum allows them to provide higher quality of services. Therefore, during the spectrum auction, the relative amount of the spectrum obtained is very important. Because of incomplete information about the amount of spectrum acquired by competitors, buyers face a major strategic problem and are exposed to the risk that the spectrum they bid is actually worth less than they have to pay for it. Exposure risk, although it is also associated with the allocation of frequencies, differs from the discussed above aggregation risk. In the first case, the buyer failed to buy the number of licenses according to their preferences. In the second one, the package they acquired may be in line with their preferences, but due to the general spectrum distribution between operators, it has definitely less value than they have to pay for it. The exposure risk is of particular importance in the markets in which only a few operators exist and allocative externalities matter (Bichler et al., 2017).

Another issue of spectrum auction designing is the fact that the seller's revenue cannot be the main criterion for assessing the effectiveness of the spectrum allocation mechanism. European directives impose an obligation on regulators to create a competitive and innovative

\footnotetext{
${ }^{3}$ The scope of the continuous spectrum translates into the quality of services provided by operators. For example, an LTE network created on the basis of a $10 \mathrm{MHz}$ band can work at a speed of $70 \mathrm{Mbps}$, and a network built on the basis of $5 \mathrm{MHz}$ will achieve a capacity of $35 \mathrm{Mbps}$ (EY, 2016).
} 
market enabling effective spectrum management ${ }^{4}$. The regulator cannot only seek to achieve maximum profit but above all they must ensure that the frequencies go to operators that are able to manage them effectively.

On the one hand, the spectrum allocation rule should be flexible enough to allow participants to achieve their preferred package of licenses, while on the other hand, it may not allow such an allocation that would violate competition on the telecommunications market. Designing auctions is, therefore, a difficult task requiring both practical experience and theoretical knowledge. Game theory comes to the rescue in this regard. By presenting the auction as a game, it is possible to model the auction, to perform a strategic analysis of bidders' behaviour and compare the effectiveness of various auction formats (Drabik, 2007).

\section{The general rules of SMRA}

The theoretical model of simultaneous multiple round ascending bid auction comes from Paul Milgrom, Robert Wilson and Preston McAffe (McMillan, 1994; Cramton, 1997). This auction is a generalization of a classic open auction (called in auction theory an English auction) to many objects, in which all goods (in this case licenses) are put up for sale simultaneously. The auction consists of consecutive rounds during which bidders submit bids for the licenses they are interested in buying. At the end of each round, the offers are classified according to their value and the results are announced together with the minimum price for each of the goods for the next round. This price is always higher than the highest offer from the previous round called the standing high bid. In the event of a tie, the winning bids are determined by the detailed regulations. The auction ends simultaneously for all sold goods when there are no buyers interested in further bidding for any of them (i.e. when there is no new offer for any of the licenses). The bidders whose offers were the highest in the last round become the owners of the auctioned goods and pay the amount they offered (Cramton, 2006).

A characteristic feature of SMRA is the activity rule. It is a mechanism that forces auction participants to actively participate in the bidding during each round. The bidder is defined as active on a specific license, if in the current round they submitted a new acceptable bid for it or if their offer for this license in the previous round was the standing high bid. The participant's activity in a given round determines their eligibility to bid in subsequent rounds. Each license has a specific number of eligibility points that reflects its value. The number of eligibility points is often determined by the scope of bandwidth or, in the case of territorial licenses (as is in the United States, for example), the size of the population in the area the license applies to. The sum of eligibility points associated with licenses on which the bidders are active in a given

\footnotetext{
${ }^{4}$ Art. 8 of Directive 2002/21/EC of the European Parliament and of the Council of 7 March 2002 on a common regulatory framework for electronic communications networks and services (Framework Directive).
} 
round determines its eligibility, i.e. the ability to bid in the next round. At the beginning of the auction, each participant determines the maximum number of licenses they are interested in buying and on this basis their maximum bidding capacity is determined. If during the bidding any of the bidders abstains from active bidding, then their bidding capacity will decrease and will never return to the initial level. If a bid is submitted that exceeds the bidder's qualification, it is rejected (Milgrom, 1998).

Several kinds of activity rules are known. The simplest of them assumes that bidders cannot increase their demand throughout the auction duration. To acquire the declared at the beginning number of licenses, maximum eligibility should be maintained throughout the entire duration of the auction, i.e. one should actively bid for this number of licenses during each of the rounds. There is also a milder version of the activity rule, the so-called stage activity rule. It allows for some delays in submitting bids in the initial stages and allows for the increase of demand in the early stages of the auction. In the original version, the stage activity rule was three-steps. In each of these stages, the buyer had to be active on a certain part (fraction) of their maximum demand submitted at the beginning of the auction to maintain their bidding rights. The fractions are increased from step to step, requiring in the final phase $100 \%$ (or similar to that level) of activity $^{5}$. If the bidder's activity drops below the level required in a given phase, then their eligibility (e.g. the rights to submit bids in subsequent rounds) decreases by a certain value specified in the regulations. The auction rules could also allow some limited number of waivers which allow the buyer to maintain eligibility even if their activity is not meeting a required level at a given stage. This allows the bidder to be inactive in the round, to take the time to plan (Milgrom, 1998; McAfee and McMillan, 1996).

The activity rule has two functions. First, it aims to encourage auction participants to raise prices, which maintains the appropriate pace of the auction. Secondly, it prevents such situations where the bidder, in order to obtain information about the valuations and preferences of its competitors, abstains from bidding in the initial phase to start bidding at the last phase of the auction. This forces bidders to be able to reveal their demands from the start of the auction, which increases the amount of available information and helps in discovering the market prices of licenses auctioned (Jääskeläinen, 2016).

\section{The advantages of SMRA}

Simultaneous multiple round ascending bid auction has some advantages compared to the two forms of spectrum allocation commonly used before SMRA introduction, which is the first price sealed bid auction and the sequential auction in the form of consecutive English auctions.

\footnotetext{
${ }^{5}$ During the FCC auctions in 1994, the required activity levels for each of the three stages was $(1 / 3,2 / 3,3 / 3)$, respectively, while at the 1998 auctions $(0.6 ; 0.8 ; 0.95)$ (Cramton, 1997; Milgrom 1998).
} 
During the first price sealed bid auction bidders cannot see each other's offers, so they have a small amount of information about rivals' valuations. This increases the risk of the winner's curse, i.e. a situation in which after the auction it turns out that the buyer overpaid for the goods more than they are worth. Auction theory says that in the face of this risk, bidders bid more carefully, which reduces the revenue from the auction (Milgrom and Weber, 1982). However, during sequential auctions, there is a risk that similar licenses will be sold at significantly different prices. This auction took place in 2000 in Switzerland, where three national licenses were sold. The first two licenses concerned the $28 \mathrm{MHz}$ block; the third was twice as large (56 MHz). Interestingly, the first license was sold for 121 million francs, the second for 134 million francs, while the third largest license was sold for 55 million francs, which is much cheaper than the smaller licenses sold before (Cramton, 2006).

A good example to confirm how important it is for the allocation method used to generate similar prices for similar products is the auction conducted in 1981 in the USA. The prices of licenses sold at that time varied considerably, which meant that bidders who paid for licenses much more than the others demanded that the regulator annul the auction due to its discriminatory nature for some bidders. As a result, the complaint has been recognized and the government decided to charge all bidders identical fees (McAfee and McMillan, 1996). A similar situation occurred also in Poland. The prices at which frequency licenses needed to provide UMTS services were sold in 2005 were definitely lower than the price paid by companies for similar licenses five years earlier. This caused strong opposition from aggrieved operators (mainly Centertel), who demanded that the regulator level fees for all entities (PTK Centertel demands..., 2005).

During simultaneous multiple round ascending bid auction buyers observe changing prices and when they reach too high levels, they can opt out of their bidding and take part in an auction of another, cheaper license. Keeping bids open for all items until the end of the auction enables bidders to flexibly change the licenses requested as prices evolve. As a result, SMRA is an auction rule conducive to efficient spectrum aggregation which, due to frequency complementarity, is its undoubted advantage (McAfee, McMillan, 1996).

Another advantage of SMRA is that during the auction process, bidders can discover the market price of the auctioned item, which, when selling licenses for multiple bands, also helps determine relative values between bands. Most of the theoretical auction models assume that buyers know their own valuation of the auctioned item, which is not always true. In practice, setting your own valuation can be quite difficult and expensive, especially when it comes to frequencies. The licenses duration is long and the technology is changing very quickly, which is why operators are not able to determine their valuation in advance. A good example could be the mentioned above series of UMTS auctions held in 2000-2001 in Europe. Not all countries have applied the format of simultaneous multiple round ascending bid auction. The prices obtained during them confirm that the valuations were then made probably relying more on the situation on the stock exchange (which was then affected by an IT bubble) and not on the basis of a thorough analysis of value (Cramton, 2013). 


\section{Other rules and properties of SMRA}

The rules of SMRA are very flexible and allow to introduce some modifications to improve its course and adapt it to the specifics of the market. One such element is the level of transparency understood as the amount of information made available to auction participants after each round. The most transparent format assumes that bidders get full information about all offers submitted by their competitors, in particular, they know all bids and corresponding bidders. This format is recognized by many theoreticians and practitioners in the field of auction design as very susceptible to collusion and strategic behaviour of bidders, which can lead to low revenues from the auction (Grimm et al., 2003). However, in certain situations, it has an advantage over other, more restrictive forms, because it allows participants to express their preferences regarding the way to distribute all spectrum available at the auction and, by appropriate bidding, to signal their reluctance to uneven and unfair distribution of licenses (Bichler et al., 2017). This is particularly important when participants face the exposure risk mentioned in Section 2. The experience gained during the 4G auction in Germany in 2015 confirms that the use of this format does not always have to fail. The participants of the German auction, thanks to the transparency of auction rules, knew the demand reported by buyers and through the way of bidding could prevent the dominant position of competitors. An analysis of the behaviour of participants in this auction confirms that they cared for the general distribution of all available spectrum and not only for the part that falls to them. Despite many strategic behaviours, this auction was successful (Bichler et al. 2017; Cramton and Ockenfels, 2017).

The less transparent type of bidding assumes that after each round, auction participants get information regarding only the highest bids (the standing high bids) for individual goods and the name of the buyer who submitted it. Even though in such cases buyers do not know exactly how competitors bid, at auctions where only a few bidders participate, on this basis some conclusions can also be drawn about the elements of strategies adopted by the rivals (Grimm et al. 2003).

In the most restrictive version of the SMRA only the highest bids for individual products and the minimum prices for the next round are available to the auction participants. This solution makes it impossible to obtain information on the demand reported by auction participants, which is not conducive to the process of discovering the market prices of the auctioned goods. In markets where there are strong allocative externalities, such a solution is not favourable (Bichler et al., 2017).

In addition to the rules described above, it is necessary to specify many other details to conduct SMRA. One of them is to determine how to set the minimum bid increment for the next round. Two approaches are used in this matter. The first is that the bidder may submit any bid provided that it is higher than the minimum amount set by the auctioneer in a given round. Another way to determine the number of bids for the next round is to increase the highest 
amount declared by a certain percentage increase. This increase may be identical for all licenses or differentiated based on the history of bidding individual licenses. The identical increment is appropriate when several similar frequency blocks are auctioned. However, when auctioned licenses differ in quality, there is a risk that some of them will enjoy less interest than others, when the speed of bidding could be accelerated by the bid increase for more active licenses (Cramton, 2006).

Another issue related to the bids submitting is to determine the manner of their entering. Currently, there is a move away from manually entering the amount of the offer in favour of systems enabling its selection from several possible options (click-box bidding). This reduces the possibility of mistakes and also reduces the possibility of using the offer to cooperate between auction participants. The click-box bidding, however, increases the risk of the tie. In this situation, two approaches are practised. In the first one, the offer that was made earlier wins $^{6}$, in the second, the winner is determined randomly (Cramton, 2006).

To promote competition and protect against market monopoly, the regulator can introduce the spectrum caps, i.e. certain restrictions on the amount of spectrum acquired on the auction. The introduction of this rule encourages new entrants and smaller companies to participate in the auction, as it increases their chances of acquiring licenses. New entrants can also be supported by reducing infrastructure costs, for example by spreading the license fee in instalments or by introducing mandatory roaming i.e. requiring incumbent operators to make their network available (for a competitive fee) to new entrants (Jehiel, Moldovanu, 2001).

Another type of support called set-asides was used by the United Kingdom during the UMTS auction in 2001, where the largest license was available only for new entrants. This instrument facilitated the entry of a new participant into the market who soon became a successful mobile network operator (Jääskeläinen, 2016).

\section{Problems arising during the spectrum auctions and ways to avoid them}

Despite the great success associated with the introduction of simultaneous multiple round ascending bid auction as a way to distribute the spectrum, the experience from such auctions around the world has shown that this format also carries some risks. One of the disadvantages of SMRA is its susceptibility to cooperation between participants. Bidders are particularly motivated to engage in tacit collusion, especially when the competition is weak. Bidders can also use various signalling strategies to allocate items at low prices (Cramton, 2013). Using the last digits of the offer as a kind of code, the auction participants can signal to others the solutions they propose regarding the way of the license distribution. This situation took place during the

\footnotetext{
${ }^{6}$ Currently, this method of tie break is rarely used. It caused buyers who become the highest bidders in a given round give reckless offers.
} 
LTE auction in Germany in 2001, where the auction participants used the last digit of the bids to inform the competitors about their preferred method of market partitioning (Grimm et al., 2003). This problem can be solved by preventing bidders from submitting their own bids of any amount in exchange for having to choose predetermined rates from the menu.

Hiding bidders identities is also a way to limit the participants' ability to communicate during the auction. This prevents strategic behaviour during auctions such as punishment strategy. Such strategies were widely used during German auctions, which were conducted using a transparent format of SMRA. Despite many fears, they did not lead to auction failure, however, according to some experts, this was a result of luck rather than a well-designed auction rule (Klemperer, 2002a; Jehiel and Moldovanu, 2001).

Competition during the auction is also a way to limit possibilities of cooperation among the bidders. Thus it is advisable to apply instruments mentioned in section 5 to encourage new entrants and small operators to take part in the action.

Setting relatively high reserve prices can also help reduce collusion. It reduces the number of rounds during which cooperation between participants can occur and also discourages the use of various bidding strategies to close the auction at low prices (Klemperer, 2002b). According to auction theory, a minimum price set at an appropriate level can increase government revenues, especially when all but one bidder has a low value of the license (Riley and Samuelson, 1981). ${ }^{7}$ In a situation where there is high uncertainty about the number of bidders, the reserve price should be approximately equal to the expected selling price. This is confirmed by the example of the Swiss $3 \mathrm{G}$ auction in 2000. There were 4 licenses sold and only 4 operators entered the auction. Reserve prices were set at a very low level and the auction ended after one round (Jääskeläinen, 2016).

Due to the complementarity of frequency blocks, the participants of SMRA are exposed to the risk related to the unfavourable spectrum assignment (aggregation risk, exposure risk). In the situation when the sold blocks do not differ significantly in terms of quality, the way to avoid the risk of fragmentation is to sell abstract (generic) blocks, i.e. blocks for which the frequency ranges are not determined in advance. The spectrum assignment process to individual operators is made after the auction. It is usually carried out by the regulatory body by way of additional proceedings while respecting the principle of effective spectrum management and taking into account the suggestions of operators.

If the quality of individual blocks differs and it is not possible to use abstract blocks, the combinatorial version of SMRA is a way to avoid the risk of aggregation and fragmentation. It allows buyers to submit bids for specific predefined spectrum packages. However, such a solution is quite difficult to implement, because often the regulator does not have sufficient knowledge about the preferences of auction participants. Moreover, at the time of

\footnotetext{
${ }^{7}$ The example of New Zealand also proves how important it is to set appropriate reserve prices. During the spectrum auction organized in 1990, no minimum prices were set, which resulted in revenues significantly lower than estimated. In particular, one license was sold for 1 New Zealand dollar (McMillan, 1994).
} 
determining the packages, the regulator often does not know who will participate. Therefore, it is difficult to divide the offered blocks into such combinations that would be in line with the bidders' preferences, while offering packages that do not match the auction participants may lead to the situation that some of them will not be sold. If it is possible to submit bids for any combination, the auction becomes complicated from both the buyer's and the seller's point of view. It causes problems for the regulator in choosing the winner of the auction because with this approach it comes down to finding a solution to a certain optimization problem, which requires a large number of numerical calculations with a large number of licenses and participants. For auction participants, combinatorial auctions also create difficulties in understanding the outcomes of individual rounds.

Another way to avoid the risk of fragmentation is to allow bidders to withdraw their bid, in particular, to allow the buyer who has the highest bid in a given block (standing high bidder) to give up this block and "switch" for another, usually cheaper block. ${ }^{8}$ This rule allows buyers to flexibly switch between blocks to get contiguous blocks or, if the buyer already has resources in this band, to apply for blocks that are adjacent to their spectrum resources. The bids withdrawal can also be used for strategic bidding, so auction rules usually allow for only a few withdrawals during the auction. Regulators often introduce some kind of "penalties" connected with bid withdrawing in the form of a difference between the amount of the withdrawn offer and the price at which license will finally sell (Cramton, 2006; McMillan, 1994). The case of the 2009 Finnish auction shows that special care should be taken during spectrum auction designing. Lack of the details in determining the conditions associated with the withdrawal of bids has led to extremely low revenues from this auction (Marsden et al., 2010).

The exposure problem during SMRA can also be reduced by supporting the process of discovering the market prices of the auctioned products. According to P. Cramton (Cramton, 2006) it is a much more effective way of combating this problem than withdrawing offers. Therefore, auction rules should include a lot of instruments supporting the price discovering process.

\section{Summary}

There is no universal auction rule that works well in each market. Adapting auction rules to the specifics of the market in which it will be used plays a key role in the auction design process. The flexibility of simultaneous multiple round ascending bid auction creates many possibilities, which is an undoubted advantage of this auction rule. However, empirical experience from spectrum auctioning shows that special care should be taken when modifying auction rules,

\footnotetext{
${ }^{8}$ The spectrum auctions with switching are especially popular in the Scandinavian countries. They took place among others, at auctions in Finland, Sweden and Norway.
} 
because even a small change could cause serious complications. In particular, it may lead to delays in the spectrum assignment which is unfavourable to the development of the telecommunications sector ${ }^{9}$.

\section{References}

1. Bichler, M., Gretschko, V., Janssen, M. (2017). Bargaining in spectrum auctions: A review of the German auction in 2015. Telecommunications Policy, 41(5-6), 325-340. doi:10.1016/j.telpol.2017.01.005.

2. Cramton, P. (1998). The Efficiency of the FCC Spectrum Auctions. Journal of Law and Economics, 41, 727-736. doi:10.1086/467410.

3. Cramton, P. (1997). The FCC Spectrum Auctions: An Early Assessment. Journal of Economics and Management Strategy, 6(3), 431-495. doi:10.1111/j.14309134.1997.00431.x.

4. Cramton, P. (2006). Simultaneous ascending auctions. In: P. Cramton, Y. Shoham, and R. Steinberg, (Eds.), Combinatorial Auctions (pp. 99-114). Cambridge: MIT Press.

5. Cramton, P. (2013). Spectrum Auction Design. Review of Industrial Organization, 42(2), 161-190. doi: 10.1007/s11151-013-9376-X.

6. Cramton, P., Ockenfels, A. (2017). The German 4G spectrum auction: Design and behaviour. The Economic Journal, 127(605), 305-324. doi: 10.1111/ecoj.12406.

7. Directive 2002/21/EC of the European Parliament and of the Council of 7 March 2002 on a common regulatory framework for electronic communications networks and services (Framework Directive).

8. Drabik, E. (2007). Aukcje w teorii $i$ w praktyce. Warsaw: Wydawnictwo SGGW.

9. EY (2016). Analiza techniczno-ekonomiczna zwiazana z efektywna alokacja pasma na polskim rynku o zakresie $800 \mathrm{MHz}$. Warsaw.

10. Grimm, V., Riedel, F., Wolfstetter, E. (2003). Low price equilibrium in multi-unit auctions: the GSM spectrum auction in Germany. International Journal of Industrial Organization, 21(10), 1557-1569. doi: 10.1016/S0167-7187(03)00058-4.

11. Jääskeläinen, J. (2016). Use of Auctions in Spectrum Awards. Aalto: Aalto University School of Business, Department of Economics.

12. Jehiel P., Moldovanu, B. (2001) The European UMTS/IMT-2000 License Auctions. Retrieved from: ftp://cramton.umd.edu/econ415/jehiel-moldovanu-european-umtsauctions.pdf, 09.05.2019.

\footnotetext{
${ }^{9}$ An excellent confirmation of this thesis is the first Polish spectrum auction, which ended in October 2015. General information about the Polish LTE auction along with characteristics of the telecommunications market in Poland should be found in the papers of A. Kuś (Kuś, 2018; 2020).
} 
13. Klemperer, P. (2002a). How (not) to run auctions: The European 3G telecom auctions. European Economic Review, 46(4), 829-845. doi: 10.1016/S0014-2921(01)00218-5.

14. Klemperer, P. (2002b). What really matters in auction design Journal of Economic Perspectives, 16(1), 169-189. doi: 10.1257/0895330027166.

15. Kuś, A. (2018). Aukcja na rezerwację częstotliwości z pasma 800 i $2600 \mathrm{MHz}$ i jej znaczenie dla rozwoju rynku telekomunikacyjnego w Polsce. Roczniki Kolegium Analiz Ekonomicznych, (49), 137-147.

16. Kuś, A. (2020). Polish experience from first ever spectrum auction. Telecommunications Policy 44(7). doi: 10.1016/j.telpol.2020.101971.

17. Lewczuk, A. (2006). Modele i własności aukcji symetrycznych. Decyzje, 6, 81-106.

18. Marsden R., Sexton E., and Siong A. (2010), 'Fixed or flexible? - A survey of $2.6 \mathrm{GHz}$ awards'. DotEcon discussion paper 10/01. Retrieved from: http://www.dotecon.com/assets/ images/dp1001.pdf, 16.05.2019.

19. McAfee, R.P., McMillan, J. (1996). Analyzing the airwaves auction. Journal of Economic Perspectives, 10(1), 159-175. doi: 10.1257/jep.10.1.159.

20. McMillan, J. (1994). Selling Spectrum Rights. Journal of Economic Perspectives, 8(3), 145-162. doi: 10.1257/jep.8.3.145.

21. Milgrom, P. (1998). Game theory and spectrum auctions. European Economic Review, 42(3-5), 771-778. doi: 10.1016/S0014-2921(97)00146-3.

22. Milgrom, P.R., Weber, R.J. (1982). A Theory of Auctions and Competitive Bidding. Econometrica, 50, 1089-1122. doi: 10.2307/1911865.

23. PTK Centertel domaga się równych dla wszystkich opłat za UMTS. Available online: https://www.money.pl/gospodarka/ngospodarka/telekomunikacja/artykul/ptk; centertel;do maga;sie;rownych;dla;wszystkich;oplat;za;umts,101,0,127845.html, 17.04.2019.

24. Riley, J.G., Samuelson, W.F. (1981). Optimal Auctions. The American Economic Review, 71, 381-392.

25. Sobolewski, M., Formański, T. (2014). Analiza symulacyjna wieloobiektowej aukcji rosnącej. Wnioski dla planowanej aukcji częstotliwości LTE w Polsce. Decyzje, 4, 95-114. doi: 10.7206/DEC.1733-0092.23. 